\title{
Erratum to: Connotations of Ecodesign: A Commentary on the State of Discourse
}

\author{
Ramani Krishnaswamy and Kumari Moothedath Chandran
}

Erratum to:

Chapter "Connotations of Ecodesign: A Commentary on the State of Discourse" in: A. Chakrabarti

and D. Chakrabarti (eds.), Research into Design

for Communities, Volume 2, Smart Innovation, Systems and Technologies 66,

DOI 10.1007/978-981-10-3521-0_35

In the original version of the book, belated corrections in Table 1 of Chapter "Connotations of Ecodesign: A Commentary on the State of Discourse" have to be incorporated. The erratum chapter and the book have been updated with the changes.

The updated online version of this chapter can be found at http://dx.doi.org/10.1007/978-981-10-3521-0_35 